Article

\title{
Comparative Analysis of the Effects of Plastic Mulch Films on Soil Nutrient, Yields and Soil Microbiome in Three Vegetable Fields
}

\author{
Xi Shan ${ }^{1,2,+}$, Wei Zhang ${ }^{1,+}$, Zhongliang Dai ${ }^{2}$, Jianbin Li ${ }^{1}$, Weiwei Mao ${ }^{3}$, Fangwei Yu ${ }^{1}$, Jinjun Ma ${ }^{4}$, \\ Shenyun Wang ${ }^{1, *}$ and Xiaoping Zeng ${ }^{4, *}$
}

Citation: Shan, X.; Zhang, W.; Dai, Z.; Li, J.; Mao, W.; Yu, F.; Ma, J.; Wang, S.; Zeng, X. Comparative Analysis of the Effects of Plastic Mulch Films on Soil Nutrient, Yields and Soil Microbiome in Three Vegetable Fields. Agronomy 2022, 12, 506. https://doi.org/ 10.3390/agronomy12020506

Academic Editors: Othmane Merah, Purushothaman Chirakkuzhyil Abhilash, Magdi T. Abdelhamid, Hailin Zhang and Bachar Zebib

Received: 10 January 2022

Accepted: 14 February 2022

Published: 17 February 2022

Publisher's Note: MDPI stays neutral with regard to jurisdictional claims in published maps and institutional affiliations.

Copyright: (C) 2022 by the authors. Licensee MDPI, Basel, Switzerland. This article is an open access article distributed under the terms and conditions of the Creative Commons Attribution (CC BY) license (https:// creativecommons.org/licenses/by/ $4.0 /)$.
1 Jiangsu Key Laboratory for Horticultural Crop Genetic Improvement, Institute of Vegetable Crops, Jiangsu Academy of Agricultural Sciences, Nanjing 210014, China; shanxi@jaas.ac.cn (X.S.); zhangwei@jaas.ac.cn (W.Z.); jbli@jaas.ac.cn (J.L.); yfw@jaas.ac.cn (F.Y.)

2 Zhenjiang Agricultural Research Institute, Zhenjiang 212400, China; daizhongliang@jaas.ac.cn

3 Nanjing Agricultural Products Quality Inspection Institute, Nanjing 210036, China; m965789324@163.com

4 Jiangsu Provincial Agricultural Technology Extension Station, Nanjing 210036, China; mjj110929@163.com

* Correspondence: wangshenyun@jaas.ac.cn (S.W.); jsnjzengxp@163.com (X.Z.)

+ These authors contributed equally to this work.

\begin{abstract}
Plastic film mulching is a common practice to increase vegetable yields. However, the effects of plastic mulch films on different vegetable fields remain largely unknown. In the current study, biodegradable mulch films (BDMs) and polyethylene mulch films (PEMs) were used to explore their effects on three vegetable fields (broccoli, chili pepper and garlic). Compared with bare soil, both BDMs and PEMs could effectively maintain higher exchangeable potassium contents in rhizosphere soil, and significantly increase various soil properties and microbial abundance both in rhizosphere and non-rhizosphere soils. In terms of yields, the treatments of BDMs and PEMs effectively increased broccoli, chili pepper and garlic yields by $17.6-19.0 \%, 21.3-23.3 \%$ and $26.0-29.5 \%$, respectively, when compared with the bare soil. Our initial characterization provided insights into the effects of BMDs and PEMs on soil properties, yields and diversity of rhizosphere and non-rhizosphere microbial communities in three vegetable fields.
\end{abstract}

Keywords: biodegradable mulch film; polyethylene mulch film; rhizosphere; soil microbe community

\section{Introduction}

A common practice of improving fruit and vegetable production is agricultural plastic mulching, which can modify soil temperatures [1], conserve moisture [2], reduce weed pressure [3] and increase yields [4-6]. Polyethylene mulch films (PEMs) are usually used in agriculture because of the low price and high durability, but the main drawback of PEMs is that it is non-degradable, and which has caused plastic film pollution and affected the planting environment [7-9]. The biodegradable mulch films (BDMs) were developed as a sustainable alternative to PEMs, which can be left for degradation in the soil without recycling, presumably solving the environmental pollution caused by PEMs [10]. BDMs provide a surface barrier prior to soil incorporation, which indirectly affects soil temperature and moisture conservation. After being used, BDMs are tilled into soil, and the soil microorganisms can then degrade the plastics [10]. BDMs are prepared from polymers, which are derived from fossil-sourced materials, plants or microbes [11]. The biobased polymers commonly used in BDMs include starch and polylactic acid (PLA) and polyhydroxyalkanoates (PHAs). The poly (butylene succinate adipate) (PBSA) and copolyesters such as poly (butylene adipate-co-terephthalate) (PBAT) are used in fossil-sourced polymers [12]. Soil microorganisms may have the capacity to degrade the polymers used in BDMs and are ultimately converted to microbial biomass and respired [12,13]. 
Plastic mulch films (include BDMs and PEMs) modify the soil microclimate, which indirectly affects soil ecosystems and the microbial community. BDMs may break down the polymers used into monomeric units under the action of microorganisms, which are eventually transformed into biomass [12]. After, they are tilled into soil, which will affect microbial biomass and enzyme activities $[14,15]$ and cause changes in microbial community structures [16-18]. Due to the incorporation of BDMs, the abundance of fungi in soil increases [17-20]. A study has also shown that fungi were enriched in one location, and Gram-positive bacteria were enriched in the other [17], which indicates that the impact of BDMs on microorganisms may be affected by the soil type, environment and farming management [10]. The researchers inferred that BDMs may affect microbial community structure and diversity, which was a similar result to PEMs from previous studies [10]. The diversification of microbial community structures and biomass under BDMs have affected the nutrient and carbon cycle in soils, which may have a long-term impact on soil organic matter. Plastic mulch films can also have effects on the nitrogen cycle and losses in soils; the nitrogen use efficiency increased by $60 \%$ under PEMs when compared with bare soil [21,22].

The present study comparatively analyzed the differences in the effects of BDMs and PEMs on the soil properties, the soil microbiome and vegetable yields (broccoli, chili pepper and garlic cultivations). Our work demonstrates biodegradable mulch films are able to provide benefits to vegetable rhizosphere environment, which lays the foundation for future agricultural production and the extended application of biodegradable mulch films.

\section{Material and Methods}

\subsection{Soil Sample Collection}

The three test crop fields of broccoli (Brassica oleracea var. italica), chili pepper (Capsicum annuum L.) and garlic (Allium sativum L.) were located in Rudong, Huai'an and Pizhou of Jiangsu Province, and were cultivated in the facilities; the soil fertility of the experimental planting sites was medium. The sowing and harvesting dates for each of the vegetables are shown in Table 1. During the harvest, the above-ground or below-ground yields of broccoli, chili pepper and garlic in all areas were collected, weighted and then converted into yields per hectare. BDMs and PEMs were used in each vegetable field with bare soil as the control. BDMs mainly composed of PBAT, with a thickness of $0.010 \mathrm{~mm}$ and width of $1.0 \mathrm{~m}$. PEMs mainly composed of polyethylene, with a thickness of $0.010 \mathrm{~mm}$ and width of $1.0 \mathrm{~m}$. The rhizosphere (at the $-20 \mathrm{~cm}$ soil layer) and non-rhizosphere (at the $0 \mathrm{~cm}$ soil layer) soils were collected from fields of broccoli, chili pepper and garlic after harvesting, respectively. The bare non-rhizosphere soils from broccoli, chili pepper and garlic were named as BANB, BANC and BANG, respectively. The bare rhizosphere soils from broccoli, chili pepper and garlic were named as BARB, BARC and BARG, respectively. The PEMs-covered non-rhizosphere soils from broccoli, chili pepper and garlic were named as PMNB, PMNC and PMNG, respectively. The PEMs-covered rhizosphere soils from broccoli, chili pepper and garlic were named as PMRB, PMRC and PMRG, respectively. The BDMs-covered non-rhizosphere soils from broccoli, chili pepper and garlic were named as BMNB, BMNC and BMNG, respectively. The BDMs-covered rhizosphere soils from broccoli, chili pepper and garlic were named as BMRB, BMRC and BMRG, respectively. All field experiments were arranged in a randomized complete block design with three biological replicates. Each treatment plot was $30 \mathrm{~m}$ in length and $1 \mathrm{~m}$ in width. All samples were divided into two parts, one for soil properties analysis, and the other for microbial community diversity analysis. 
Table 1. Sowing and harvesting dates of broccoli, chili pepper and garlic in the experiment.

\begin{tabular}{ccc}
\hline Vegetables Fields & Sowing Date & Harvesting Date \\
\hline Broccoli & January, 2020 & May, 2020 \\
Chili pepper & November, 2019 & May, 2020 \\
Garlic & September, 2019 & May, 2020 \\
\hline
\end{tabular}

\subsection{Determination of Soil Properties}

Soil samples were analyzed for organic matter, ammonium-N, nitrate-N, alkali-hydrolyzed$\mathrm{N}$, exchangeable potassium and available phosphorus following standard soil testing procedures [23] by the Chinese Agricultural Laboratory. The potassium dichromate oxidation external heat method was used to determine the contents of the soil organic matter. The ammonium- $\mathrm{N}$ and nitrate- $\mathrm{N}$ were determined by potassium chloride extraction, and alkalihydrolyzed-N was measured with thealkaline hydrolysis diffusion method. Ammonium acetate extraction was used to determine the exchangeable potassium, and the available phosphorus was determined by the sodium bicarbonate extraction. The main instruments used in the experiment were spectrophotometer (MAPADA UV-1200, Shanghai, China), microplate reader (SpectraMax 190, Molecular Devices, Sunnyvale, CA, USA) and flame luminometer (HG-5, BMG LABTECH, Ortenberg, Germany).

\subsection{Sequences Processing and Analysis}

The soil samples were analyzed by Biomarker Technologies Corporation (Beijing, China) for high-throughput sequencing. The 16S rRNA and the internal transcribed spacers (ITS1) region were reliably used in the analysis of soil bacterial and fungal communities, respectively. After the sequencing, the FLASH v1.2.7 software (http:/ / ccb.jhu.edu/software/ FLASH/) (accessed on 9 July 2020) was used to splice the reads of each sample through overlap. Trimmomatic v0.33 (http:/ / www.usadellab.org/cms/index.php?page=trimmomatic) (accessed on 9 July 2020) and UCHIME v4.2 software (http:/ / drive5.com/uchime) (accessed on 9 July 2020) were used to filter the raw tags from the splicing to obtain highquality tags and to remove the chimera sequences for obtaining the final effective tags, respectively. The tags were clustered into Operational Taxonomic Units (OTUs) with a 97\% threshold using Usearch software (http:/ / www.drive5.com/usearch/) (accessed on 9 July 2020) [24]. Species annotations were made on representative sequences of OTUs, sequences of bacterial OTUs selected SILVA database [25] (http:/ / www.arb-silva.de) (accessed on 9 July 2020) and sequences of fungal OTUs selected UNITE database [26] (Release 8.0, https: / / unite.ut.ee/) (accessed on 9 July 2020), and both used the RDP Classifier approach [27] (version 2.2, http:/ / sourceforge.net/projects/rdpclassifier/) (accessed on 9 July 2020) for species annotation analysis.

\subsection{Diversity Analysis}

For $\alpha$-diversity analysis, the microbial community's richness (Chao1, ACE indices, Shannon and Simpson index) of every single sample was determined using the MOTHUR software [28] (version v.1.30, http:/ / www.mothur.org/) (accessed on 9 July 2020). Chao1 and ACE indices measured species richness in samples [29]. Shannon and Simpson indices were used to measure species diversity, which is affected by species abundance and community evenness in the sample communities. We used Mothur (http:/ / www.mothur.org) (accessed on 9 July 2020) and R software to draw the Shannon diversity index rarefaction curve according to the Shannon index of the sequencing quantity of each sample at different sequencing depths.

For $\beta$-diversity analysis, the differences of samples in species complexity were evaluated; non-metric multi-dimensional scaling (NMDS) [30,31] is a sorting method suitable for ecological research. The Bray-Curtis, weighted Unifrac and unweighted Unifrac distances were calculated by QIIME software (v1.80) (http:/ / qiime.org/) (accessed on 9 July 2020). The analysis of variance was finished by $\mathrm{R}$ packages. The differences between the two 
samples were shown as color change. After standardized processing, the top 80 species were selected according to OTU data. Each color block represented the abundance of a genus of a sample, with samples arranged horizontally and species arranged vertically.

\subsection{Statistical Analysis}

These data were analyzed by the SPSS 20.0 software (SPSS Inc., Chicago, IL, USA). The Duncan's new multiple range test $(p<0.05)$ was applied.

\section{Results}

3.1. Effects of Different Covered Plastic Mulch Films on the Properties of Rhizosphere and Non-Rhizosphere Soils

The soil properties were different on BDMs, PEMs and bare soils in three vegetable fields (Table 2). In the fields of broccoli, the contents of organic matter in BMNB were significantly higher than that in PMNB, while the contents of nitrate nitrogen in BMRB were significantly higher than that in BARB and PMRB. In the chili pepper field, the content of nitrate-N in PMRC and BMRC was significantly higher than that in BARC, respectively. In the garlic field, the content of organic matter in PMRG was significantly higher than that in BMRG and BARG. The content of exchangeable potassium in PMNG was significantly higher than that in BMNG, and that in BMRG was significantly lower than that in PMRG. In the early stage, BDMs were intact and had similar effects to PEMs.

\subsection{Soil Microbiome Analysis}

In order to explore the microbiome of rhizosphere and non-rhizosphere soil under BDMs and PEMs treatment, we analyzed the microbiome of these soils with three test crops at three different areas (Rudong, Huai'an and Pizhou) in the Jiangsu province. A total of 4,319,853 paired-end reads were obtained in bacterial community (Supplementary materials: Table S1), and 4,059,195 effective tags were obtained after we filtered out low-quality reads, with 75,170 tags per sample on average (range: 72,669-77,922 tags), and the proportions of effective tags were greater than $90 \%$. A total of 3,830,133 paired-end reads were obtained in the fungal community, and 3,495,050 effective tags were obtained after we filtered out low-quality reads, with 64,723 tags per sample on average (range: 40,396-77,488 tags), and the proportions of effective tags were greater than $76 \%$. The similarity of effective tags higher than $97 \%$ were defined as OTU, and a total of 103,773 OTUs were obtained in bacterial communities, while 27,255 were obtained in fungal communities. The bacterial communities from broccoli, chili pepper and garlic fields shared 2207, 1596 and 2115 OTUs under different treatments, respectively (Figure 1; Supplementary materials: Table S2). In addition, the OTUs of fungal communities from broccoli, chili pepper and garlic fields were 866,238 and 233, respectively. 
Table 2. Soil properties in three different vegetable fields under different treatments.

\begin{tabular}{|c|c|c|c|c|c|c|c|}
\hline Vegetables & Treatments & $\begin{array}{l}\text { Organic Matter } \\
(\mathrm{g} / \mathrm{kg})\end{array}$ & $\underset{(\mathrm{mg} / \mathrm{kg})}{\text { Ammonium-N }}$ & $\begin{array}{c}\text { Nitrate-N } \\
(\mathrm{mg} / \mathrm{kg})\end{array}$ & $\begin{array}{c}\text { Alkaline } \\
\text { Hydrolysis-N } \\
\text { (mg/kg) }\end{array}$ & $\begin{array}{l}\text { Exchangeable } \\
\text { Potassium } \\
\text { (mg/kg) }\end{array}$ & $\begin{array}{c}\text { Available } \\
\text { Phosphorus } \\
\text { (mg/kg) }\end{array}$ \\
\hline \multirow{5}{*}{ Broccoli } & BANB & $11.80 \pm 0.72^{\mathrm{ab}}$ & $1.11 \pm 0.20 \mathrm{ab}$ & $8.03 \pm 1.30^{b}$ & $69.00 \pm 7.23^{a}$ & $109.33 \pm 16.05^{a}$ & $44.83 \pm 9.58^{a}$ \\
\hline & BMNB & $13.10 \pm 0.45^{\mathrm{a}}$ & $0.92 \pm 0.03^{\mathrm{ab}}$ & $10.44 \pm 3.98^{b}$ & $81.67 \pm 3.93^{a}$ & $127.33 \pm 10.81^{a}$ & $58.30 \pm 13.25^{a}$ \\
\hline & BMRB & $12.53 \pm 0.18^{a b}$ & $1.12 \pm 0.06^{\mathrm{ab}}$ & $31.13 \pm 5.90^{\mathrm{a}}$ & $78.00 \pm 2.08^{a}$ & $134.67 \pm 10.04^{\mathrm{a}}$ & $53.40 \pm 7.21^{a}$ \\
\hline & PMNB & $11.23 \pm 0.42^{b}$ & $0.78 \pm 0.70^{b}$ & $9.92 \pm 1.07^{b}$ & $59.33 \pm 0.88^{a}$ & $103.67 \pm 6.89^{\mathrm{a}}$ & $33.67 \pm 3.44^{\mathrm{a}}$ \\
\hline & PMRB & $11.23 \pm 0.45^{b}$ & $1.36 \pm 0.24^{\mathrm{a}}$ & $18.51 \pm 3.44^{b}$ & $70.00 \pm 18.04^{a}$ & $144.33 \pm 32.04^{\mathrm{a}}$ & $49.40 \pm 9.77^{\mathrm{a}}$ \\
\hline \multirow{6}{*}{ Chili pepper } & BANC & $11.13 \pm 0.63^{a}$ & $4.14 \pm 1.70^{\mathrm{a}}$ & $17.19 \pm 2.31^{b}$ & $64.23 \pm 2.52^{b}$ & $199.83 \pm 25.98^{a}$ & $66.8 \pm 5.67^{b}$ \\
\hline & BARC & $11.73 \pm 0.94^{\mathrm{a}}$ & $2.55 \pm 0.26^{\mathrm{ab}}$ & $21.05 \pm 1.55^{\mathrm{ab}}$ & $67.97 \pm 2.00^{a b}$ & $110.337 \pm 7.49^{b}$ & $70.03 \pm 5.66^{a b}$ \\
\hline & BMNC & $12.03 \pm 1.02^{\mathrm{a}}$ & $1.21 \pm 0.14^{\mathrm{ab}}$ & $23.35 \pm 0.63^{\mathrm{ab}}$ & $72.70 \pm 1.01^{\mathrm{ab}}$ & $189.47 \pm 16.74^{\mathrm{a}}$ & $72.80 \pm 1.36^{a b}$ \\
\hline & BMRC & $12.30 \pm 0.99^{a}$ & $1.01 \pm 0.08^{b}$ & $27.59 \pm 1.91^{\mathrm{a}}$ & $74.33 \pm 3.54^{\mathrm{ab}}$ & $108.90 \pm 2.17^{b}$ & $70.43 \pm 0.37^{a b}$ \\
\hline & PMNC & $13.00 \pm 2.51^{\mathrm{a}}$ & $1.73 \pm 0.42^{\mathrm{ab}}$ & $22.88 \pm 3.59^{a b}$ & $71.40 \pm 6.70^{\mathrm{ab}}$ & $188.60 \pm 22.93^{a}$ & $82.57 \pm 5.13^{a}$ \\
\hline & PMRC & $13.83 \pm 2.88^{\mathrm{a}}$ & $2.19 \pm 0.10^{\mathrm{ab}}$ & $26.62 \pm 1.90^{\mathrm{a}}$ & $78.87 \pm 6.28^{a}$ & $126.07 \pm 22.79^{b}$ & $75.03 \pm 5.67 \mathrm{ab}$ \\
\hline \multirow{4}{*}{ Garlic } & BANG & $14.37 \pm 0.91^{b}$ & $2.03 \pm 0.22^{b}$ & $15.51 \pm 2.35^{\mathrm{c}}$ & $86.20 \pm 5.81^{a}$ & $196.93 \pm 4.23^{\mathrm{a}}$ & $70.14 \pm 4.82^{b c}$ \\
\hline & BARG & $16.57 \pm 0.88^{b}$ & $2.74 \pm 0.14^{\mathrm{a}}$ & $16.87 \pm 0.96^{b c}$ & $87.27 \pm 6.46^{a}$ & $170.07 \pm 3.79^{b}$ & $77.87 \pm 1.69^{a b}$ \\
\hline & PMNG & $15.67 \pm 1.07^{b}$ & $2.42 \pm 0.28^{a b}$ & $22.99 \pm 2.06^{\mathrm{a}}$ & $87.63 \pm 6.38^{a}$ & $202.50 \pm 12.03^{a}$ & $71.80 \pm 2.81^{b c}$ \\
\hline & PMRG & $21.77 \pm 1.32^{\mathrm{a}}$ & $2.52 \pm 0.04^{\mathrm{ab}}$ & $21.62 \pm 1.25^{\mathrm{a}}$ & $85.87 \pm 5.24^{a}$ & $191.50 \pm 9.12^{\mathrm{ab}}$ & $83.23 \pm 1.32^{\mathrm{a}}$ \\
\hline
\end{tabular}

Note: Different lowercase letters in one vegetable field indicate significant differences $(p<0.05)$. 


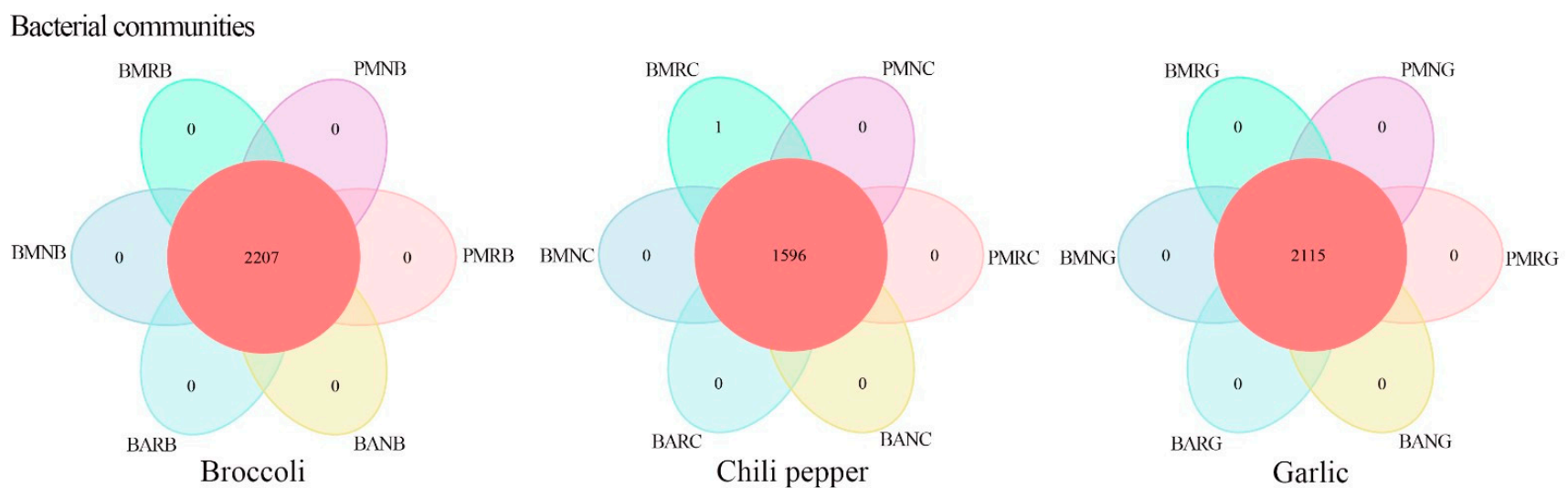

Fungal communities

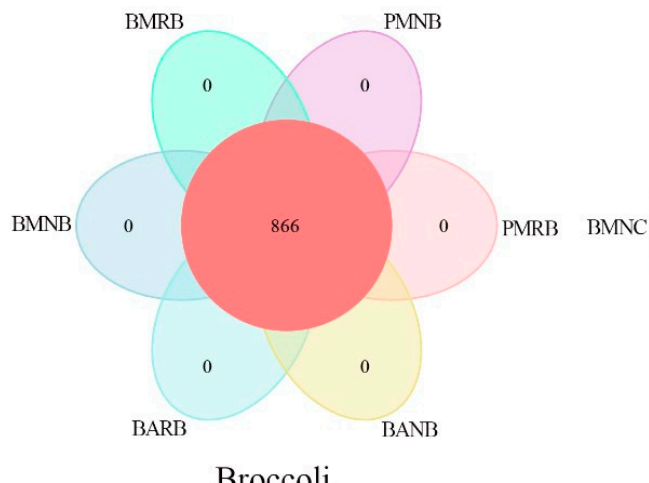

Broccoli

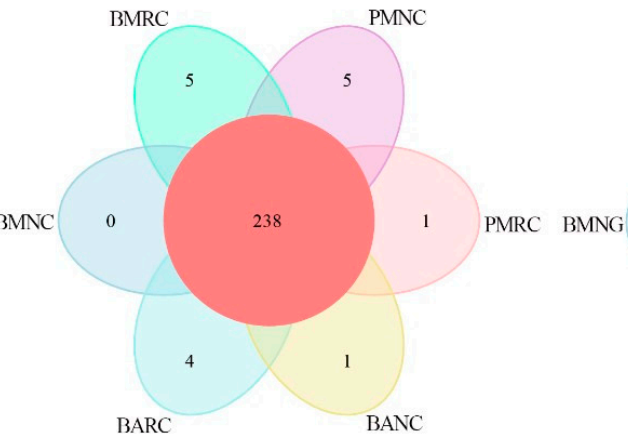

Chili pepper

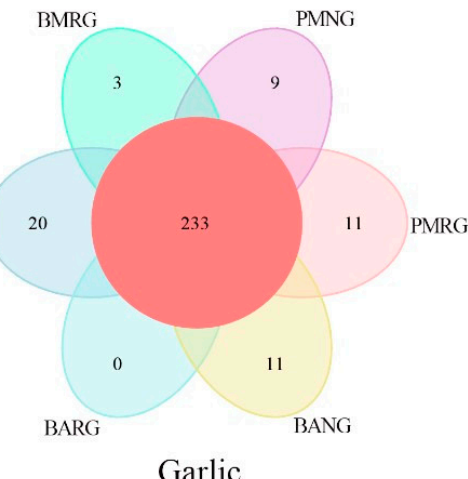

Garlic

Figure 1. OTU numbers of common bacteria and fungi in three vegetable fields under different treatments.

\section{3. $\alpha$-Diversity Comparison among Different Samples}

In the garlic fields of Pizhou, for the ACE index estimates, there was a significant difference between the non-rhizosphere soil of BDMs and bare soil samples. The bacterial communities of non-rhizosphere soil covered with BDMs significantly increased (Figure 2; Supplementary materials: Table S3). The Shannon's diversity index in PMRG was significantly lower than that in PMNG, which showed that the bacterial community diversity in rhizosphere soil was higher than that in non-rhizosphere soil. Additionally, the Shannon in PMRG was significantly lower than BMRG, indicating that the non-rhizosphere soil bacterial community diversity in the BDMs was higher than that in the PEMs. In addition, the OTU coverage was also calculated. The coverages of all samples were higher than 0.99 , which indicated that the probability of the species in the samples being detected was very high, but the probability of not being detected was very low. This showed that the sequencing results represent the true conditions of the samples. The rarefaction curve of all samples tended to be flat, reflecting that the sample sequencing depth basically covered all the microorganisms (Supplementary materials: Figure S1).

In the broccoli fields of Rudong (Supplementary materials: Table S3; Figures S2 and S3), for the ACE and Chao1 indices in the fungal community, the values in BMRB were significantly higher than that in BARB, which showed that the abundance of fungal species in rhizosphere soil covered with PEMs was significantly higher than that in bare soil. The Shannon's diversity index in BMNB was significantly higher than that in BANB, indicating that the fungal community diversity of non-rhizosphere soil under PEMs was higher than that in bare soil. In the garlic fields of Pizhou (Figure 2), the ACE and Chao1 indices in BMRG were higher than those in PMRG, which indicated that the abundance of fungal species have diversity in rhizosphere soil under BDMs and PEMs treatments. 

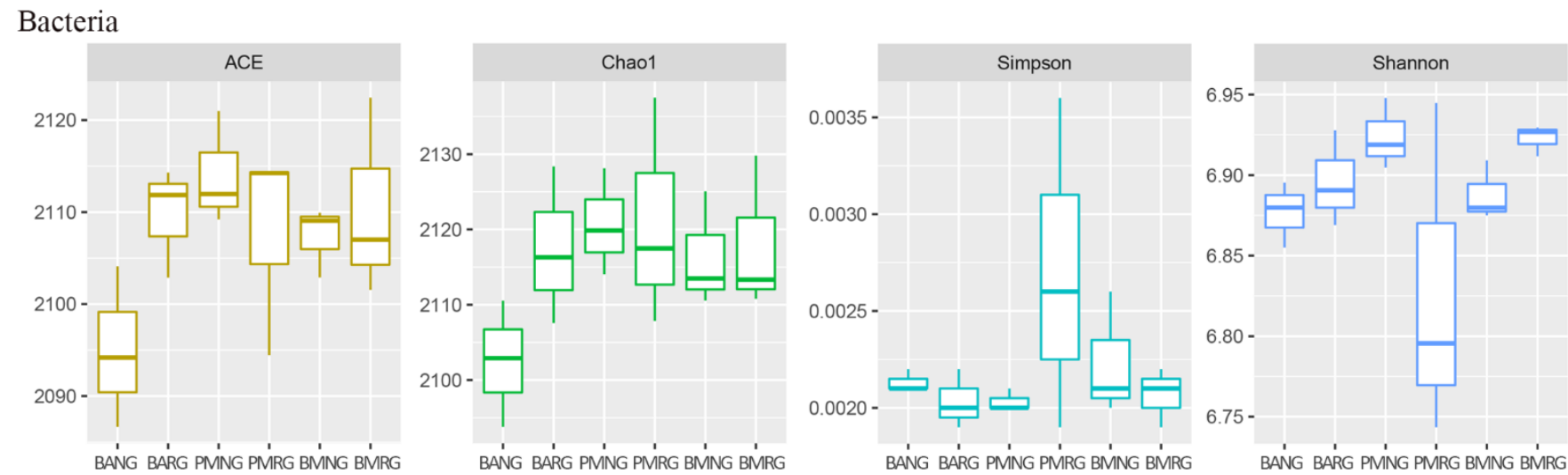

Fungi
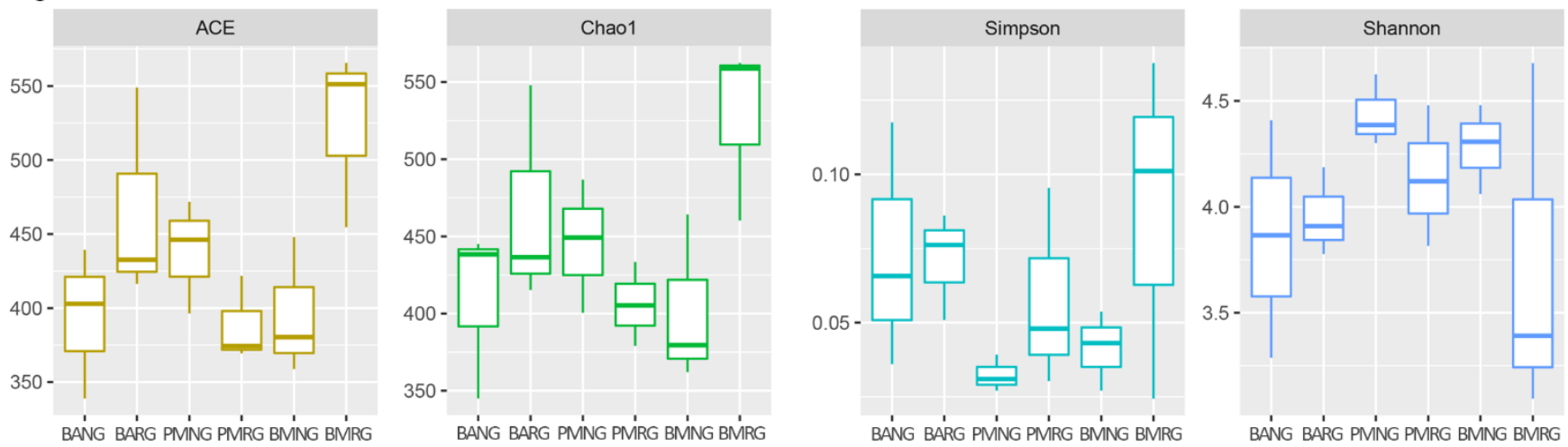

Figure 2. The $\alpha$-diversity of bacteria and fungi in garlic field under different treatments.

\section{4. $\beta$-Diversity Comparison among Different Samples}

In Figure 3 and Supplementary materials: Table S4, the $\beta$-diversity analysis of soil bacterial communities showed differences between bare and different films covered in rhizosphere and non-rhizosphere soil (weighted UniFrac, 0.10; unweighted UniFrac, 0.04; Bray-Curtis, 0.25 ) in the fields of broccoli, followed by the differences in the fields of chili pepper (weighted UniFrac, 0.08; unweighted UniFrac, 0.08; Bray-Curtis, 0.25), and the differences in the fields of garlic (weighted UniFrac, 0.04; unweighted UniFrac, 0.01; BrayCurtis, 0.15). The $\beta$-diversity analysis of fungi communities was based on the Bray-Curtis algorithm. The results showed the differences between broccoli (Bray-Curtis, 0.41), chili pepper (Bray-Curtis, 0.25) and garlic (Bray-Curtis, 0.34) fields.

Based on these algorithms, the distance matrixes between samples were obtained. According to the change of color gradient, the differences between samples can be seen intuitively. The color gradient from blue to red indicated the distance between samples from near to far. NMDS analysis of bacteria based on Bray-Curtis revealed significant differences in rhizosphere and non-rhizosphere soils covered with different mulches (Figure 3). In the broccoli fields of Rudong, the color of non-rhizosphere soil samples covered by BDMs and PEMs were lighter, indicating that the distance between samples was closer, while the similarity of bacteria in non-rhizosphere soil covered by mulches was higher, but the difference of bacteria in non-rhizosphere soil was greater. In the rhizosphere soil, the samples covered by BDMs and bare soil were lighter in color, and farther away from the soil samples covered by PEMs, indicating that the similarity of bacteria between BDMs and bare soil samples. In the chili pepper fields of Huai'an, the differences of bacteria between the non-rhizosphere and rhizosphere soil covered by BDMs and PEMs were also similar, but they were quite different from those of bare soil samples. In the garlic fields of Pizhou, the similarity of bacteria in bare soil and BDMs covered non-rhizosphere soil samples was higher, while that in covered soil, the BDMs- and PEMs-covered rhizosphere soil was higher. 


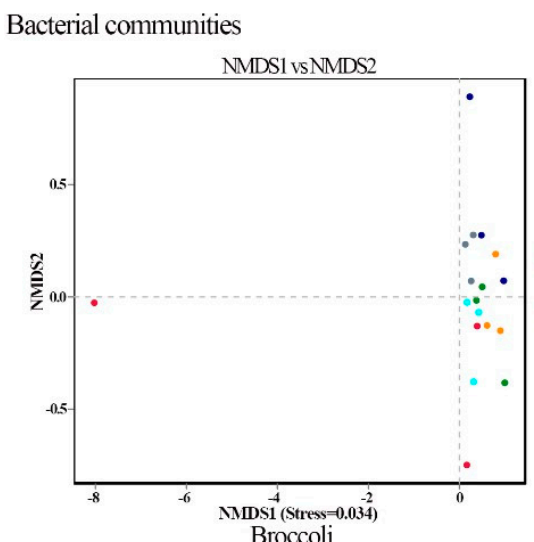

Fungal communities

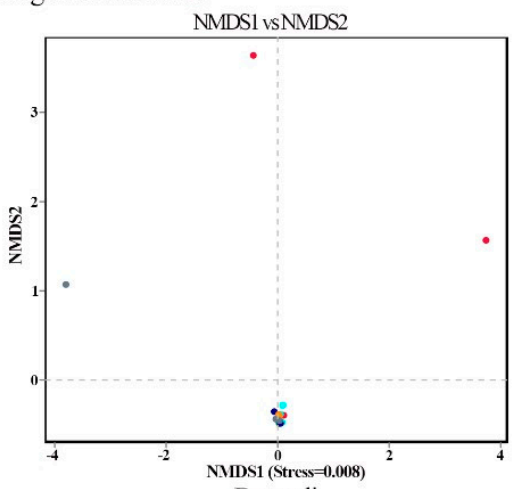

Broccoli
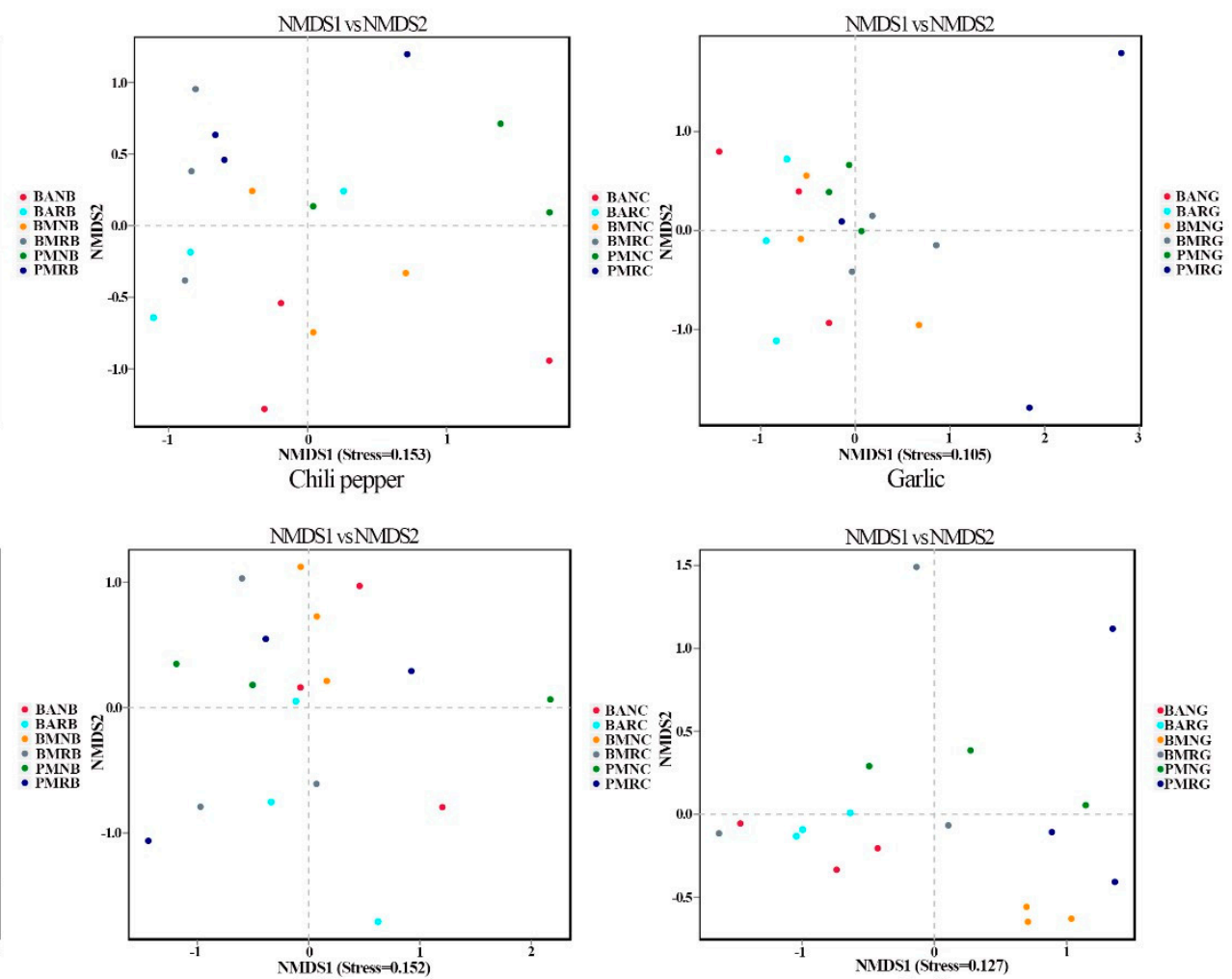

Chili pepper

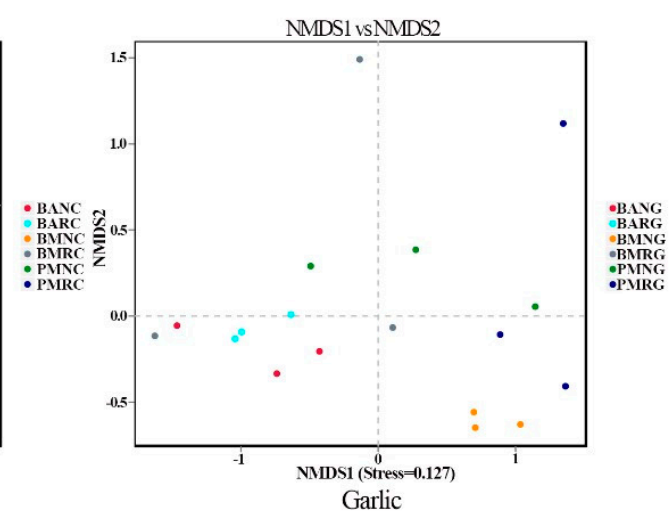

Figure 3. Non-metric multi-dimensional scaling (NMDS) analysis in three different vegetable fields under different treatments.

NMDS analysis of fungi based on the Bray-Curtis algorithm revealed significant differences in rhizosphere and non-rhizosphere soils covered with different mulches (Figure 4). In the broccoli fields of Rudong, the similarity of fungi was higher in the samples of nonrhizosphere soil covered by BDMs and PEMs, while the difference was greater than that in bare soils. In the rhizosphere soil samples, the fungi similarity between bare soil and PEMscovered soil was higher. In the garlic fields of Pizhou, fungi in rhizosphere soil covered by BDMs and PEMs were similar, but different from those in bare rhizosphere soil, and similar in non-rhizosphere soil. In the chili pepper fields of Huai'an, in the non-rhizosphere soil samples, the fungi in the covered BDMs, PEMs and bare soils were similar. In rhizosphere soil samples, the fungi of BDMs and PEMs were similar, while they were quite different from bare soil samples. 


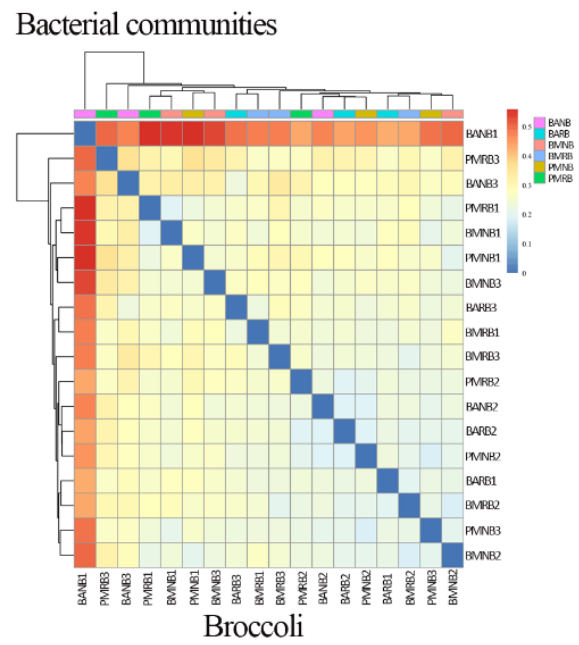

Fungal communities

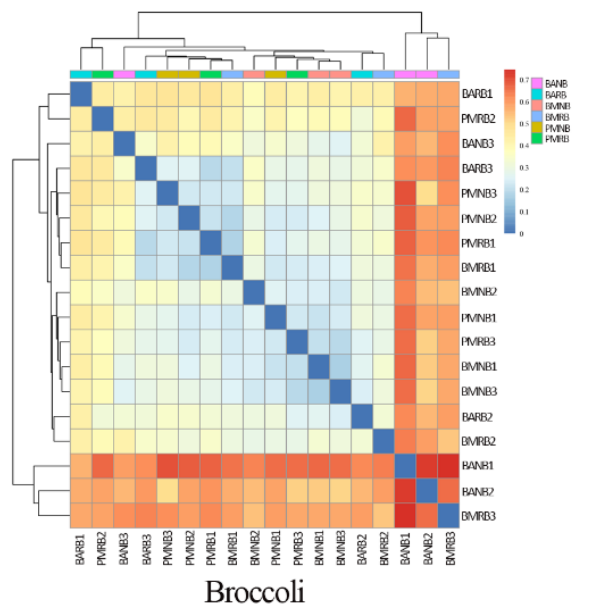

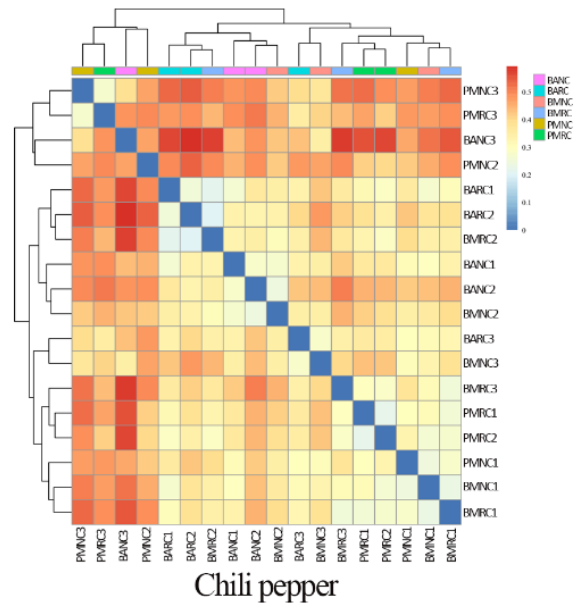
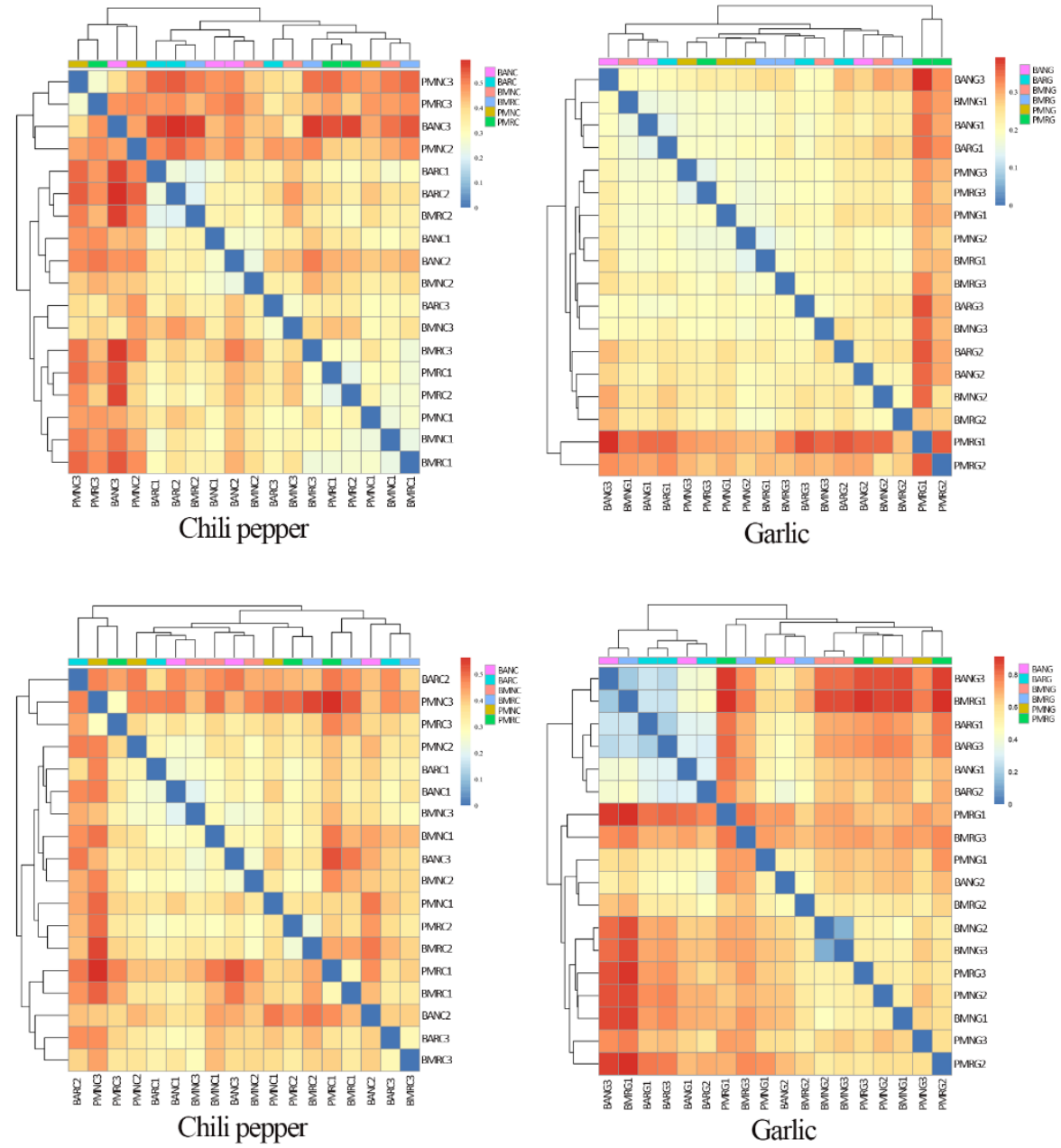

Figure 4. Bray-Curtis distance analysis in three different vegetable fields under different treatments.

3.5. Effects of Mulch Films on Rhizosphere and Non-Rhizosphere Soil Microbial Community Composition

At the phylum level, 10 bacterial phyla in samples under different treatments were counted (Figure 5; Supplementary materials: Table S5). Proteobacteria, Acidobacteria, Chloroflexi, Gemmatimonadetes, Bacteroidetes, Actinobacteria and Verrucomicrobia were the major phyla associated with all non-rhizosphere and rhizosphere soils in all treatments. Proteobacteria was the most abundant, with more than $30.5 \%$ of the total bacterial taxa in all samples. Acidobacteria accounted for $18.8-25.4 \%$ of all bacterial taxa in the broccoli fields of Rudong, while they accounted for $12.3-14.3 \%$ in the garlic fields of Pizhou. In the chili pepper fields of Huai'an, Patescibacteria accounted for $8.8-14.8 \%$ of all bacterial taxa, followed by Chloroflexi and Gemmatimonadetes in the fields of Rudong, Pizhou and Huai'an. The relative abundance of bacteria phylum varied in bare soils, BDMs-covered and PEMs-covered soils. At the taxonomic level of the genus, Sphingomonas was found to have the highest relative abundance in the chili pepper fields of Huai'an (Figure 6; Supplementary materials: Table S6). In the broccoli fields of Rudong, the relative abundance of Proteobacteria and Acidobacteria in PMRB were higher than BARB and BMRB, while PMRB had lower relative abundance of Chloroflexi, Gemmatimonadetes, Bacteroidetes, Planctomycetes, Verrucomicrobia and Latescibacteria than BARB and BMRB. The Proteobacteria and Planctomycetesc had lower relative abundance in PMRC than BARC and BMRC. The relative abundance of Patescibacteria and Chloroflexi were higher in PMRC than BARC and BMRC. In contrast, the relative abundance of Proteobacteria, Bacteroidetes, Nitrospirae and Verrucomicrobia were 
higher in PMRG than BARG and BMRG, while PMRG had lower relative abundance in Gemmatimonadetes and Actinobacteria than BARG and BMRG.
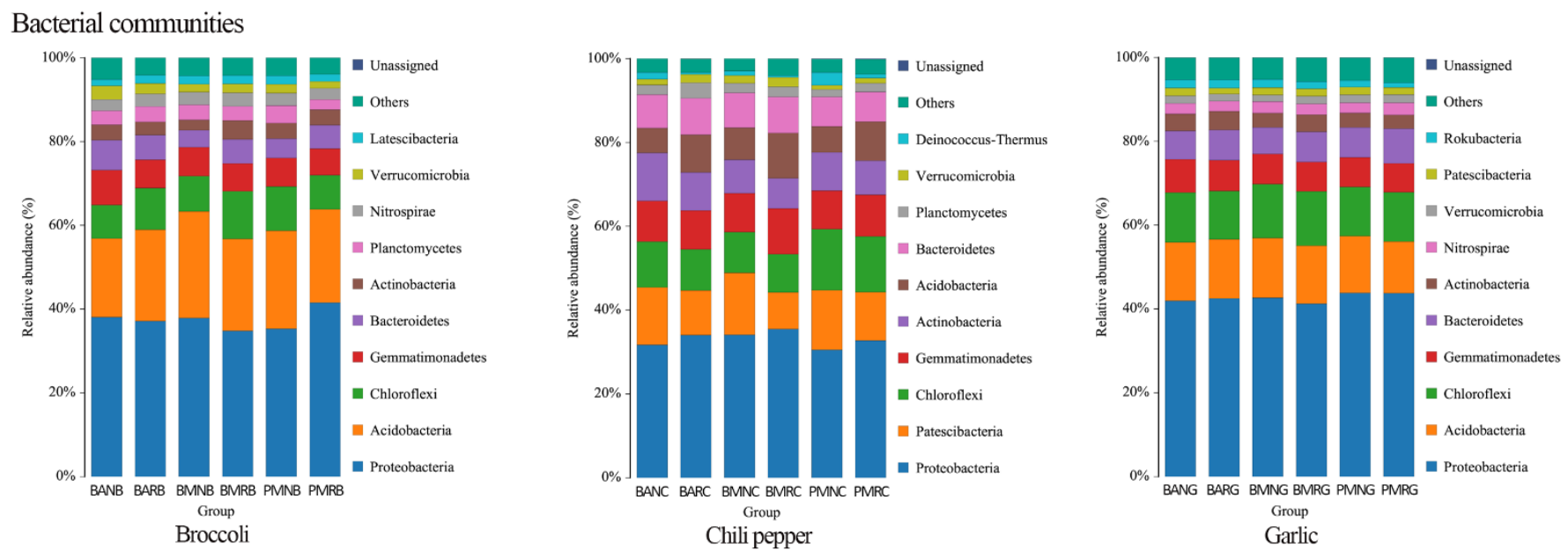

Fungal communities
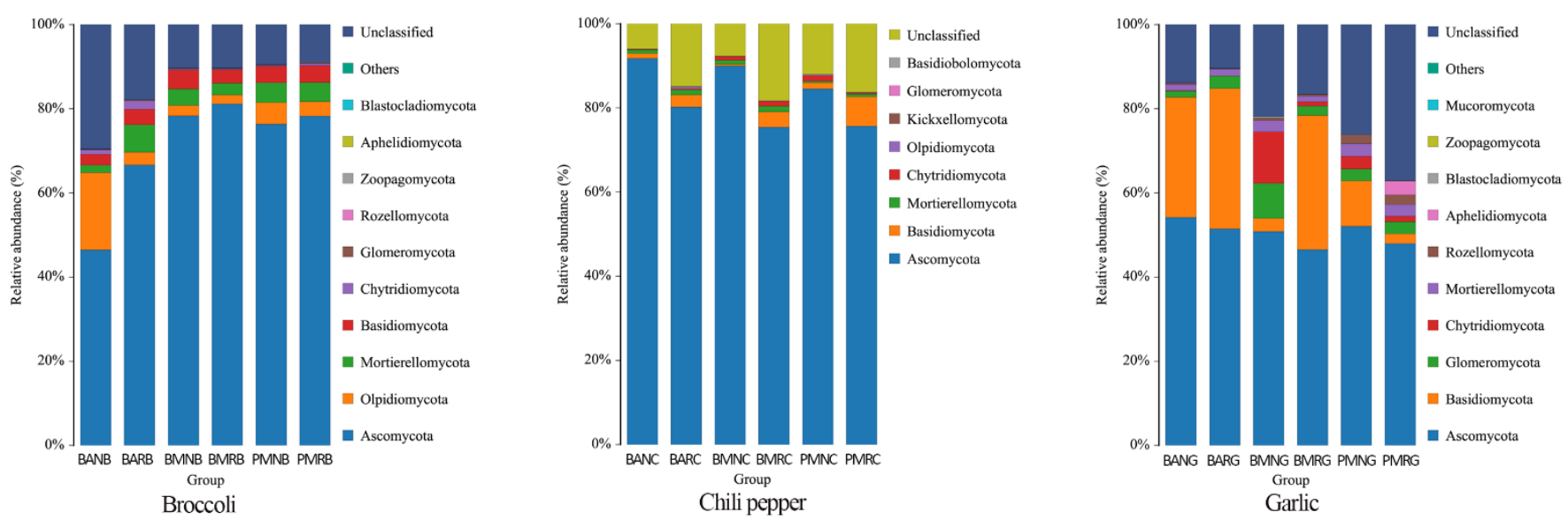

Figure 5. The composition and relative abundance of bacterial and fungal communities at phylum level in three different vegetable fields under different treatments.

At the phylum level, eight fungal phyla were identified in all samples under different treatments (Figure 5; Supplementary materials: Table S5). Ascomycota, Mortierellomycota, Basidiomycota, Chytridiomycota and Glomeromycota were identified in all samples. The Ascomycota phylum was the most abundant fungi phyla in our samples, accounting for $46.5-91.7 \%$ of total fungi taxa in all non-rhizosphere and rhizosphere soil samples. The second dominant phylum was Olpidiomycota, followed by Mortierellomycota and Basidiomycota in the broccoli fields of Rudong. Basidiomycota was the second most abundant fungi phylum in the fields of Huai'an and Pizhou, followed by Mortierellomycota and Glomeromycota, which presented in the fields of Huai'an and Pizhou, respectively. At the taxonomic level of the genus, Cladosporium, Fusarium and Acremonium were the predominant fungi genus in the fields of Huai'an and Pizhou (Figure 6; Supplementary materials: Table S6). The fungi phyla relative abundances were various in bare soils, BDMs- and PEMs-covered soils. The relative abundance of Olpidiomycota, Basidiomycota, Glomeromycota and Zoopagomycota were higher in PMRB than BARB and BMRB. Ascomycota and Rozellomycota had a lower relative abundance in PMRB than BMRB, while it was higher than BARB. The relative abundance of Basidiomycota, Kickxellomycota and Glomeromycota were higher in PMRC than BARC and BMRC. Mortierellomycota had a lower relative abundance in PMRC than BARC and BMRC. Other fungi phyla in the fields of Huai'an showed differences. The relative abundance of Basidiomycota was lower in PMRG than in BARG and BMRG. Chytridiomycota, 
Mortierellomycota, Rozellomycota, Aphelidiomycota and Blastocladiomycota had a higher relative abundance in PMRG than in BARG and BMRG.
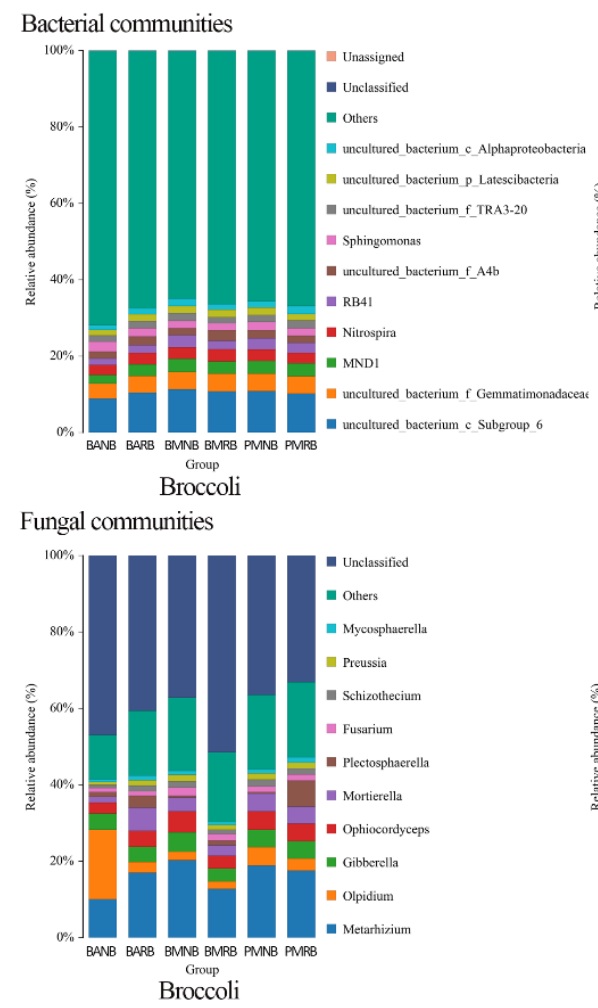
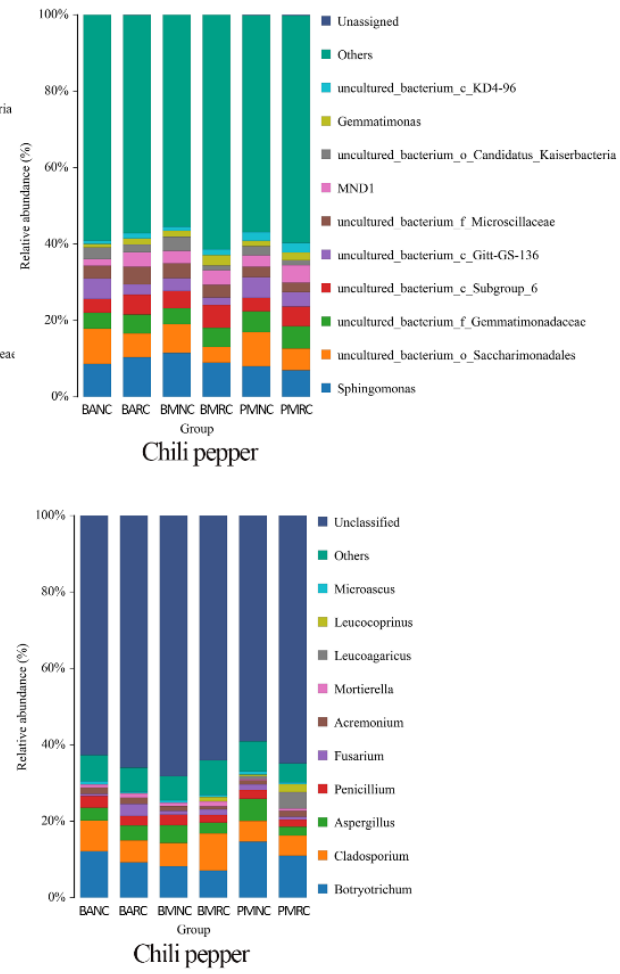
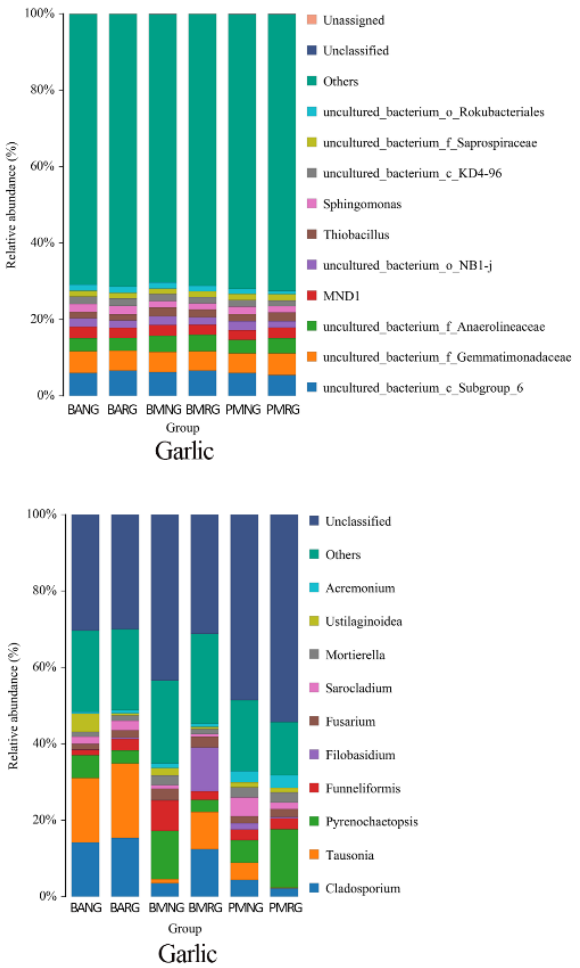

Figure 6. The composition and relative abundance of bacterial and fungal communities at genus level in three different vegetable fields under different treatments.

\subsection{Effects of Mulch Films on Crop Yields}

In order to determine the effect of different plastic mulch films on crop yields, we measured the equivalent yields of broccoli, chili pepper and garlic under different treatments (Table 3). The BDMs and PEMs treatments significantly increased the yields of broccoli and chili pepper, while there was no significant difference between the BDMs and PEMs treatments. The yields of broccoli treated with BDMs and PEMs were $979.1 \mathrm{~kg} / 667 \mathrm{~m}^{2}$ and $990.7 \mathrm{~kg} / 667 \mathrm{~m}^{2}$, which were $17.6 \%$ and $19.0 \%$ higher than bare soil control, respectively. The yields of chili pepper $\left(3255.0 \mathrm{~kg} / 667 \mathrm{~m}^{2}\right.$ and $\left.3202.7 \mathrm{~kg} / 667 \mathrm{~m}^{2}\right)$ under PEMs and BDMs treatment were $23.3 \%$ and $21.3 \%$ higher than bare soil, respectively. The yields of garlic treated with PEMs contained the highest yield of $1541.3 \mathrm{~kg} / 667 \mathrm{~m}^{2}$, followed by BDMs treatment and bare soil. The yields of garlic under PEMs and BDMs treatments were 29.5\% and $26.0 \%$ higher than bare soil, respectively. This indicated that the plastic mulch films significantly increased the yields of broccoli, chili pepper and garlic.

Table 3. Yields comparison of broccoli, chili pepper and garlic under different treatments $\left(\mathrm{kg} / \mathrm{hm}{ }^{2}\right)$.

\begin{tabular}{ccccc}
\hline & Treatment Methods & Broccoli & Chili Pepper & Garlic \\
\hline \multirow{3}{*}{ Yields $\left(\mathrm{kg} / \mathrm{hm}^{2}\right)$} & Bare soil & $12,487.0 \pm 292.4^{\mathrm{b}}$ & $39,605.0 \pm 400.4^{\mathrm{b}}$ & $17,852.5 \pm 346.2^{\mathrm{b}}$ \\
& BDMs treatment & $14,686.0 \pm 396.6^{\mathrm{a}}$ & $48,040.0 \pm 848.7^{\mathrm{a}}$ & $22,487.0 \pm 388.0^{\mathrm{a}}$ \\
& PEMs treatment & $14,860.5 \pm 310.9^{\mathrm{a}}$ & $48,825.0 \pm 575.3^{\mathrm{a}}$ & $23,119.5 \pm 599.2^{\mathrm{a}}$ \\
\hline
\end{tabular}

Note: Different letters in lower case represent significant differences $(p<0.05)$ among bare soil, PEMs and BDMs treatments.

\section{Discussion}

Agricultural plastic mulch films are able to provide a favorable microclimate environment for plant growth, improve soil microbial structure and increase crop yields 
and quality [32,33]. In recent years, BDMs have become increasingly widely used and emerged as a sustainable substitute for PEMs. We observed that BDMs and PEMs treatments increased the contents of nitrate nitrogen in broccoli and chili pepper fields, while the opposite results were found in garlic field (Table 2). Previous studies have shown that the impact of BDMs on soil properties varies from a number of factors, including location, time and planting systems [34,35]. Mulch film incorporation can improve the mineralization rate of organic nitrogen in soil $[36,37]$. As the soil nutrient and crop growth conditions are improved, it is more conducive to the nutrient absorption capacity of crops. Sintim et al. (2019) monitored effects of BDMs on nitrate nitrogen, which decreased in two fall seasons, and these differences may be attributed to absorption capacity of different plants. During plant growth, the soil surface was protected by mulch films, which affected nitrate nitrogen loss through leaching or surface runoff [21,22]. While in the garlic field, the contents of available potassium under BDMs treatment were significantly lower than that under PEMs treatment (Table 2), which could not indicate BDMs were inferior to PEMs. Both soil properties and initial spatial variations have implications for the design and analysis of the experiment. From these soil properties we determined that the BDMs and PEMs might have similar effects on soil environment. When analyzed with raw data of the soil properties, mulch films had significant effects on chemical soil health; in contrast, exchangeable potassium has biologic and fertility effects on the soil health when using change scores [38]. We would use more statistical methods to assess the soil properties to reduce the range of errors in future investigations. Considering this limitation, we found that mulch films have a significant influence on soil microbes and their processes by changing the crop microclimate environment, thus improving crop productivity [9].

It was shown that the effects of the BDMs did not accumulate over time, but were masked by the effects of time; mulch films and the planting system significantly effect nitrate nitrogen [38], which is probably due to seasonal tillage operations, as tillage resets many soil properties, affecting soil chemistry and fertility [39-41], while mulch films may indirectly affect the soil ecosystems through modification of the soil microclimate [10]. Several studies have shown that there were no significant differences in soil microbial community structures covered by BDMs and PEMs [34], in contrast to other studies on BDMs [16,18] and PEMs [42,43], which have observed significant effects. There were significant differences in bacterial composition in the soil at different locations and seasons, which indicates that the type of mulch film has little impact on the microbial community. We did note significant differences in soil bacterial and fungal composition between geographical locations and growing vegetables. In this study, the six phyla Proteobacteria, Bacteroidetes, Acidobacteria, Actinobacteria, Gemmatimonadetes and Chloroflex were dominant bacteria in all soil samples of the broccoli, chili pepper and garlic fields (Figure 5). In the rhizosphere soil of Arabidopsis, the phyla Proteobacteria, Bacteroidetes, Actinobacteria, Acidobacteria, Firmicutes, Gemmatimonadetes and Cyanobacteria dominated [44]. The main bacterial communities in bare rhizosphere soil were Actinobacteria, Bacteroidetes and Proteobacteria [45]. According to the microbiome analysis, it has been found in the soil samples of maize, oat, cactus, potato, sugar beet and oak [46,47] that the phyla Proteobacteria, Bacteroidetes, Acidobacteria, Actinobacteria and Chloroflex were dominant bacterial communities in the rhizosphere of these plants. It has been shown that location and season have a greater impact on soil bacterial composition than mulch films effects [30]. While in our study, in the rhizosphere of broccoli, the phylum Actinobacteria in soil covered with BDMs was higher than that in PEMs and bare soil control (Figure 5). Streptomyces sp. in Actinobacteria, which have been shown to have polymer degradation capabilities [48]. However, we observed no difference in the relative abundance of the Actinobacteria phylum in chili pepper and garlic fields (Figure 5), which may be related to farming time for different crops that often reset many soil properties causing fluctuating abundance of some bacterial phyla. In the rhizosphere of chili pepper, Proteobacteria in BDMs0covered soil were more abundant than in PEMs and bare soil. Consistent with the results of Farmer et al. (2017), Sreejata et al. (2018) also showed that Proteobacteria was a dominant phylum for enrichment in BDMs. In 
the rhizosphere of garlic, the relative abundance of Chloroflexi in BDMs was higher than that in PEMs and bare soils. Chloroflexi was a widely reported heterotrophic oligotrophic and facultative anaerobes bacteria with the ability to degrade large molecules into small molecular organic compounds [49].

The abundances of gene copy in the soils were often indicated by the abundances of bacteria and fungi. In our study, the abundances of several fungi phyla were different between mulch films and bare soils. We found that fungi of the phyla Ascomycota, Mortierellomycota, Basidiomycota, Chytridiomycota and Glomeromycota were dominant in all soil samples of broccoli, chili pepper and garlic fields (Figure 5). Studies have shown that poly (butylene-adipate-co-terephthalate) film (one kind of BDMs) was preferentially enriched in Ascomycota [18], as the BDMs incorporated into the soils, the soil environment (such as soil warming) was affected [32], and the abundance of fungi increased [17-20]. Ascomycota is the most abundant and dominant phylum in fungal communities, which is the main decomposer of soil organic matter (humus, straw, branches, etc.), and has important ability to decompose lignocellulose [50,51]. In garlic fields, the relative abundance of Basidiomycota in the rhizosphere soil covered by BDMs was higher than that of PEMs (Figure 5), but the relative abundance of Basidiomycota of covered soil was lower than that of bare soils. Basidiomycota also has the ability to break down lignocellulose, but it is an oligotrophic microorganism and is adapted to relatively poor soil [52], so the abundance was inversely proportional to C/N [53]. However, the impact of BDMs on fungi is affected by the environment, soil type and soil management [10,54].

Through the three different vegetable cultivations, our research showed that both the BDMs and PEMs could increase the yields of broccoli, chili pepper and garlic (Table 3). There was no significant difference between BDMs and PEMs treatments, but in terms of garlic, the yields of BDMs were significantly lower than PEMs treatment, although both of them were higher than bare soil. A three-year field experiment showed that both BDMs and the common plastic films could increase the yields of maize and cotton [55]. Considering the environmental protection concerns, BDMs were favorable to PEMs. However, the effects of BDMs vary in different seasons and different management conditions, as well as the subsequent effects on soil properties, which will be explored in our future research.

\section{Conclusions}

Taken together, we found that film mulching increased the contents of exchangeable potassium and nitrate nitrogen in broccoli and chili pepper rhizosphere soils. The soils from BDMs and PEMs had greater microbial diversity than bare soil. Using bare soil as the control, BDMs and PEMs effectively increased vegetable yields by $17.6-26.0 \%$ and $19.0-29.5 \%$, respectively. The BDMs showed similar effects to PEMs. From the environmental protection perspective, BDMs were superior to PEMs. These results will provide a theoretical basis for growers and regulators from the perspective of soil properties, microorganisms and yields.

Supplementary Materials: The following supporting information can be downloaded at: https: / / www.mdpi.com/article/10.3390/agronomy12020506/s1, Figure S1. The rarefaction curves of bacteria and fungi in broccoli, garlic and chili pepper fields under different treatments; Figure S2. The $\alpha$-diversity of bacteria and fungi in the broccoli field under different treatments; Figure S3. The $\alpha$-diversity of bacteria and fungi in the chili pepper field under different treatments; Table S1. Sequencing results of common bacteria and fungi in three vegetable fields under different treatments; Table S2. The OTU abundance in broccoli, garlic and chili pepper fields under different treatments; Table S3. The ACE, Chao1, Simpson, Shannon and Coverage indices in broccoli, garlic and chili pepper fields under different treatments; Table S4. The $\beta$-diversity in broccoli, garlic and chili pepper fields under different treatments; Table S5. Relative abundance of dominate phyla in broccoli, garlic and chili pepper fields under different treatments. Table S6. Relative abundance of the dominate genus in broccoli, garlic and chili pepper fields under different treatments. 
Author Contributions: S.W. and X.Z. conceived and supervised the work. X.S. and W.Z. performed the bioinformatics analysis and drafted the manuscript. F.Y., Z.D., J.L., W.M. and J.M. provided guidance and manuscript reviews. All authors have read and agreed to the published version of the manuscript.

Funding: This work was in part supported by the Fifth '333 Project' Scientific Research Foundation of Jiangsu Province (BRA2020365), the Agricultural Project of Jiangsu Province (2019-SJ-012, 2020-SJ-015), the Jiangsu Science and Technology Project (BE2020403).

Informed Consent Statement: Not applicable.

Data Availability Statement: Availability of data have been deposited into the NCBI BioProject database under accession numbers SUB10184895.

Acknowledgments: We thank Jie Zhou for a critical reading of this manuscript.

Conflicts of Interest: The authors declare no conflict of interest.

\section{References}

1. Kasirajan, S.; Ngouajio, M. Polyethylene and biodegradable mulches for agricultural applications: A review. Agron. Sustain. Dev. 2012, 32, 501-529. [CrossRef]

2. Kader, M.A.; Senge, M.; Mojid, M.A.; Ito, K. Recent advances in mulching materials and methods for modifying soil environment. Soil Tillage Res. 2017, 168, 155-166. [CrossRef]

3. Martín-Closas, L.; Costa, J.; Pelacho, A.M. Agronomic effects of biodegradable films on crop and field environment. In Soil Degradable Bioplastics for a Sustainable Modern Agriculture; Malinconico, M., Ed.; Springer: Berlin/Heidelberg, Germany, 2017; pp. 67-104.

4. Ren, X.L.; Zhang, P.; Chen, X.L.; Jia, Z.K. Impacts of ridge-furrow rainfall concentration systems and mulches on corn growth and yield in the semiarid region of China. J. Sci. Food Agric. 2016, 96, 3882-3889. [CrossRef] [PubMed]

5. Ren, X.L.; Zhang, P.; Chen, X.L.; Guo, J.J.; Jia, Z.K. Effect of Different Mulches under Rainfall Concentration System on Corn Production in the Semi-arid Areas of the Loess Plateau. Sci. Rep. 2016, 6, 19019. [CrossRef]

6. Braunack, M.V.; Adhikari, R.; Freischmidt, G.; Johnston, P.; Filipovi, V. Initial experimental experience with a sprayable biodegradable polymer membrane (SBPM) technology in cotton. Agronomy 2020, 10, 584. [CrossRef]

7. Abel, D.; Kloas, W.; Zarfl, C.; Stefan, H.; Matthias, C. Microplastics as an emerging threat to terrestrial ecosystems. Glob. Chang. Biol. 2018, 24, 1405-1416.

8. Qian, H.; Meng, Z.; Liu, G.F.; Lu, T.; Qu, Q.; Du, B.; Pan, X. Effects of Soil Residual Plastic Film on Soil Microbial Community Structure and Fertility. Water Air Soil Pollut. 2018, 229, 261. [CrossRef]

9. Steinmetz, Z.; Wollmann, C.; Schaefer, M.; Buchmann, C.; David, J.; Troger, J. Plastic mulching in agriculture. Trading short-term agronomic benefits for long-term soil degradation? Sci. Total Environ. 2016, 550, 690-705. [CrossRef]

10. Sreejata, B.; Lluis, M.C.; Pelacho, A.M. Biodegradable Plastic Mulch Films: Impacts on Soil Microbial Communities and Ecosystem Functions. Front. Microbiol. 2018, 9, 819.

11. Marechal, F. Biodegradable plastics. In Biodegradable Polymers and Plastics; Chiellini, E., Solaro, R., Eds.; Springer: New York, NY, USA, 2003.

12. Brodhagen, M.; Peyron, M.; Miles, C.; Inglis, D.A. Biodegradable plastic agricultural mulches and key features of microbial degradation. Appl. Microbiol. Biotechnol. 2015, 99, 1039-1056. [CrossRef]

13. Kyrikou, I.; Briassoulis, D. Biodegradation of agricultural plastic films: A critical review. J. Polym. Environ. 2007, 15, 125-150. [CrossRef]

14. Li, C.; Moore-Kucera, J.; Lee, J.; Corbin, A.; Brodhagen, M.; Miles, C. Effects of biodegradable mulch on soil quality. Appl. Soil Ecol. 2014, 79, 59-69. [CrossRef]

15. Yamamoto-Tamura, K.; Hiradate, S.; Watanabe, T.; Koitabashi, M.; Sameshima-Yamashita, Y.; Yarimizu, T. Contribution of soil esterase to biodegradation of aliphatic polyester agricultural mulch film in cultivated soils. AMB Express 2015, 5, 10. [CrossRef] [PubMed]

16. Koitabashi, M.; Noguchi, M.; Sameshima-Yamashita, Y.; Hiradate, S.; Suzuki, K. Degradation of biodegradable plastic mulch films in soil environment by phylloplane fungi isolated from gramineous plants. AMB Express 2012, 2, 40. [CrossRef]

17. Li, C.; Moore-Kucera, J.; Miles, C.; Leonas, K.; Lee, J.; Corbin, A. Degradation of potentially biodegradable plastic mulch films at three diverse US locations. Agroecol. Sustain. Food Syst. 2014, 38, 861-889. [CrossRef]

18. Muroi, F.; Tachibana, Y.; Kobayashi, Y.; Sakurai, T.; Kasuya, K. Influences of poly(butylene adipate-co-terephthalate) on soil microbiota and plant growth. Polym. Degrad. Stab. 2016, 129, 338-346. [CrossRef]

19. Rychter, P.; Biczak, R.; Herman, B.; Smylla, A.; Kurcok, P.; Adamus, G. Environmental degradation of polyester blends containing atactic poly(3-hydroxybutyrate). Biodegradation in soil and ecotoxicological impact. Biomacromolecules 2006, 7, 3125-3131. [CrossRef] 
20. Ma, Z.; Ma, Y.; Qin, L.; Liu, J.; Su, H. Preparation and characteristics of biodegradable mulching films based on fermentation industry wastes. Int. Biodeterior. Biodegrad. 2016, 111, 54-61. [CrossRef]

21. Qin, W.; Hu, C.; Oenema, O. Soil mulching significantly enhances yields and water and nitrogen use efficiencies of maize and wheat: A meta-analysis. Sci. Rep. 2015, 5, 16210. [CrossRef]

22. Nan, W.; Yue, S.; Huang, H.; Li, S.; Shen, Y. Effects of plastic film mulching on soil greenhouse gases $\left(\mathrm{CO}_{2}, \mathrm{CH}_{4}\right.$ and $\left.\mathrm{N}_{2} \mathrm{O}\right)$ concentration within soil profiles in maize fields on the Loess Plateau, China. J. Integr. Agric. 2016, 15, 451-464. [CrossRef]

23. Lu, R.K. The Analysis Method of Soil Agricultural Chemistry; China Agricultural Science and Technology Press: Beijing, China, 2000; pp. 146-190.

24. Edgar, R. UPARSE: Highly accurate OTU sequences from microbial amplicon reads. Nat. Methods 2013, 10, 996. [CrossRef]

25. Quast, C.; Pruesse, E.; Yilmaz, P.; Gerken, J.; Schweer, T.; Yarza, P.; Peplies, J.; Glöckner, F. The SILVA ribosomal RNA gene database project: Improved data processing and web-based tools. Nucleic Acids Res. 2012, 41, D590-D596. [CrossRef] [PubMed]

26. Koljalg, U.; Nilsson, R.; Abarenkov, K.; Tedersoo, L.; Taylor, A.; Bahram, M.; Bates, S. Towards a unified paradigm for sequencebased identification of fungi. Mol. Ecol. 2013, 22, 5271-5277. [CrossRef] [PubMed]

27. Wang, Q.; Garrity, G.; Tiedje, J.; Cole, J. Naive Bayesian classifier for rapid assignment of rRNA sequences into the new bacterial taxonomy. Appl. Environ. Microbiol. 2007, 73, 5261-5267. [CrossRef] [PubMed]

28. Chao, A. Nonparametric estimation of the number of classes in a population. Scand. J. Stat. 1984, 11, 265-270.

29. Zhou, D.; Feng, H.; Schuelke, T.; De Santiago, A.; Zhang, Q.; Zhang, J. Rhizosphere microbiomes from root knot nematode non-infested plants suppress nematode infection. Microb. Ecol. 2019, 78, 470-481. [CrossRef]

30. Looft, T.; Johnson, T.; Allen, H. In-feed antibiotic effects on the swine intestinal microbiome. Proc. Natl. Acad. Sci. USA 2012, 109, 1691-1696. [CrossRef]

31. Qiao, Q.; Wang, F.; Zhang, J.; Chen, Y.; Zhang, C.; Liu, G. The variation in the rhizosphere microbiome of cotton with soil type, genotype and developmental stage. Sci. Rep. 2017, 7, 3940. [CrossRef]

32. Sreejata, B.; González, J.; Henderson, K.; Anunciado, M.; Hayes, D.; DeBruyn, J. Soil Microbial Communities Associated With Biodegradable Plastic Mulch Films. Front. Microbiol. 2020, 11, 587074.

33. Jordan, A.; Zavala, L.; Munoz-Rojas, M. Mulching, effects on soil physical properties. In Encyclopedia of Earth Sciences; Springer: Dordrecht, The Netherlands, 2011; pp. 492-496.

34. Kapanen, A.; Schettini, E.; Giuliano, V.; Itävaara, M. Performance and environmental impact of biodegradable films in agriculture: A field study on protected cultivation. J. Polym. Environ. 2008, 16, 109-122. [CrossRef]

35. Moreno, M.; Moreno, A. Effect of different biodegradable and polyethylene mulches on soil properties and production in a tomato crop. Sci. Hortic. 2008, 116, 256-263. [CrossRef]

36. Bowen, P.; Frey, B. Response of plasticultured bell pepper to staking, irrigation frequency, and fertigated nitrogen rate. Hort. Sci. 2002, 37, 95-100. [CrossRef]

37. Romic, D.; Romic, M.; Borosic, J. Mulching decreases nitrate leaching in bell pepper cultivation. Agric. Water Manag. 2003, 60, 87-97. [CrossRef]

38. Sintim, H.; Bandopadhyay, S.; English, M.; Bary, A.; DeBruyn, J. Impacts of biodegradable plastic mulches on soil health. Agric. Ecosyst. Environ. 2019, 273, 36-49. [CrossRef]

39. Zuber, S.; Behnke, G.; Nafziger, E.; Villamil, M. Crop rotation and tillage effects on soil physical and chemical properties in Illinois. Agron. J. 2015, 107, 971-978. [CrossRef]

40. Alam, M.; Islam, M.; Salahin, N.; Hasanuzzaman, M. Effect of tillage practices on soil properties and crop productivity in wheat-mungbean-rice cropping system under subtropical climatic conditions. Sci. World J. 2014, 2014, 437283. [CrossRef] [PubMed]

41. Busari, M.; Kukal, S.; Kaur, A.; Bhatt, R.; Dulazi, A. Conservation tillage impacts on soil, crop and the environment. Int. Soil Water Conserv. Res. 2015, 3, 119-129. [CrossRef]

42. Farmer, J.; Zhang, B.; Jin, X.; Zhang, P.; Wang, J. Long-term effect of plastic film mulching and fertilization on bacterial communities in a brown soil revealed by high through-put sequencing. Arch. Agron. Soil Sci. 2017, 63, 230-241. [CrossRef]

43. Munoz, K.; Schmidt-Heydt, M.; Stoll, D.; Diehl, D.; Ziegler, J.; Geisen, R.; Schaumann, G.E. Effect of plastic mulching on mycotoxin occurrence and mycobiome abundance in soil samples from asparagus crops. Mycotoxin Res. 2015, 31, $191-201$.

44. Lundberg, D.; Lebeis, S.; Paredes, S.; Yourstone, S.; Gehring, J.; Malfatti, S. Defining the core Arabidopsis thaliana root microbiome. Nature 2012, 488, 86-90. [CrossRef]

45. Bulgarelli, D.; Garrido-Oter, R.; Münch, P.; Weiman, A.; Dröge, J.; Pan, Y. Structure and function of the bacterial root microbiota in wild and domesticated barley. Cell Host Microbe 2015, 17, 392-403. [CrossRef] [PubMed]

46. Mendes, R.; Garbeva, P.; Raaijmakers, J. The rhizosphere microbiome: Significance of plant beneficial, plant pathogenic and human pathogenic microorganisms. FEMS Microbiol. Rev. 2013, 37, 634-663. [CrossRef] [PubMed]

47. Weinert, N.; Piceno, Y.; Ding, G.; Meincke, R.; Heuer, H.; Berg, G. PhyloChip hybridization uncovered an enormous bacterial diversity in the rhizosphere of different potato cultivars: Many common and few cultivar-dependent taxa. FEMS Microbiol. Ecol. 2011, 75, 497-506. [CrossRef] [PubMed]

48. Pathak, V.M.; Navneet. Review on the current status of polymer degradation: A microbial approach. Bioresour. Bioprocess. 2017, 4, 15. [CrossRef] 
49. Xu, M.; Xian, Y.; Wu, J.; Gu, Y.; Yang, G.; Zhang, X. Effect of biogas slurry addition on soil properties, yields, and bacterial composition in the rice-rape rotation ecosystem over 3 years. J. Soils Sediments 2019, 19, 2534-2542. [CrossRef]

50. Souza, R.; Mendes, I.; Reis-Junior, F.; Carvalho, F.; Nogueira, M.; Vasconcelos, A.; Vicente, V.A.; Hungria, M. Shifts in taxonomic and functional microbial diversity with agriculture: How fragile is the Brazilian Cerrado? BMC Microbiol. 2016, 16, 42. [CrossRef] [PubMed]

51. Wang, F.; Liang, Y.; Jiang, Y. Planting increases the abundance and structure complexity of soil core functional genes relevant to carbon and nitrogen cycling. Sci. Rep. 2015, 5, 14345. [CrossRef]

52. Sun, Q.; Rui, W.; Hu, Y.; Yao, L.; Guo, S.; Jorge, P. Spatial variations of soil respiration and temperature sensitivity along a steep slope of the semiarid Loess Plateau. PLoS ONE 2018, 13, e0195400. [CrossRef]

53. Procter, A.; Ellis, J.; Fay, P.; Polley, H.; Jackson, R. Fungal community responses to past and future atmospheric $\mathrm{CO}_{2}$ differ by soil type. App. Environ. Microbiol. 2014, 80, 7364-7377. [CrossRef]

54. Bandopadhyay, S.; Sintim, H.Y.; DeBruyn, J.M. Structural and Functional Responses of Soil Microbial Communities to Biodegradable Plastic Film Mulching in Two Agroecosystems. BioRxiv 2019, 5, 650317.

55. Deng, L.; Yu, Y.; Zhang, H.; Wang, Q.; Yu, R. The Effects of Biodegradable Mulch Film on the Growth, Yield, and Water Use Efficiency of Cotton and Maize in an Arid Region. Sustainability 2019, 11, 7039. [CrossRef] 